\title{
Production and characterization of extracellular carbohydrate polymer from Cyanothece sp. CCY 0110
}

\author{
Rita Mota a , Rodrigo Guimarães ${ }^{\mathrm{a}}$, Zsófia Büttel $^{\mathrm{a}}$, Federico Rossi ${ }^{\mathrm{b}}$, Giovanni Colica ${ }^{\mathrm{b}}$, Carla J. Silva $^{\mathrm{c}}$, \\ Carla Santos $^{c}$, Luís Gales ${ }^{\mathrm{a}, \mathrm{d}}$, Andrea Zille ${ }^{\mathrm{a}, 1}$, Roberto De Philippis ${ }^{\mathrm{b}}$, Sara B. Pereira ${ }^{\mathrm{a}}$, Paula Tamagnini ${ }^{\mathrm{a}, \mathrm{e}, *}$ \\ a IBMC - Instituto de Biologia Molecular e Celular, Universidade do Porto, Rua do Campo Alegre 823, 4150-180 Porto, Portugal \\ ${ }^{\mathrm{b}}$ Department of Agricultural Biotechnology, University of Florence, Piazzale delle Cascine 24, I-50144 Florence, Italy \\ c Centro de Nanotecnologia e Materiais Técnicos, Funcionais e Inteligentes (CeNTI), Rua Fernando Mesquita 2785, 4760-034 Vila Nova de Famalicão, Portugal \\ d Instituto de Ciências Biomédicas Abel Salazar (ICBAS), Universidade do Porto, Rua de Jorge Viterbo Ferreira 228, 4050-313 Porto, Portugal \\ e Faculdade de Ciências, Departamento de Biologia, Universidade do Porto, Rua do Campo Alegre, Edifício FC4, 4169-007 Porto, Portugal
}

\section{A R T I C L E I N F O}

\section{Article history:}

Received 12 July 2012

Received in revised form 22 October 2012

Accepted 28 October 2012

Available online 3 November 2012

\section{Keywords:}

Cyanobacteria

Cyanothece

Extracellular polymeric substances (EPS)

Released polysaccharides (RPS)

\begin{abstract}
A B S T R A C T
Cyanobacterial extracellular polymeric substances (EPS) are heteropolysaccharides that possess characteristics suitable for industrial applications, notably a high number of different monomers, strong anionic nature and high hydrophobicity. However, systematic studies that unveil the conditions influencing EPS synthesis and/or its characteristics are mandatory. In this work, Cyanothece sp. CCY 0110 was used as model organism. Our results revealed that this strain is among the most efficient EPS producers, and that the amount of RPS (released polysaccharides) is mainly related to the number of cells, rather than to the amount produced by each cell. Light was the key parameter, with high light intensity enhancing significantly RPS production (reaching $1.8 \mathrm{~g} \mathrm{~L}^{-1}$ ), especially in the presence of combined nitrogen. The data showed that RPS are composed by nine different monosaccharides (including two uronic acids), the presence of sulfate groups and peptides, and that the polymer is remarkably thermostable and amorphous in nature.
\end{abstract}

(c) 2012 Elsevier Ltd. All rights reserved.

\section{Introduction}

Cyanobacteria, like a wide range of other microorganisms, are able to synthesize and secrete extracellular polymeric substances (EPS) mainly constituted by heteropolysacchärides. These EPS can remain associated with the cell surface as sheaths, capsules and/or slimes, or be released into the surrounding environment as released polysaccharides (RPS). It has been hypothesized that they might be involved in the protection of the cells, the formation of biofilms, and/or the sequestration/immobilization of metal ions (Parker, Schram, Plude, \& Moore, 1996; Pereira et al., 2009; Sutherland, 1999). Cyanobacterial EPS have distinctive characteristics compared to those produced by other microorganisms: (i) contain generally 6-10 different monomers increasing the number of possible structural conformations of the polymer, (ii) have a strong

\footnotetext{
* Corresponding author at: IBMC - Instituto de Biologia Molecular e Celular, Universidade do Porto, Rua do Campo Alegre 823, 4150-180 Porto, Portugal. Tel.: +351226074900; fax: +351226099157.

E-mail address: pmtamagn@ibmc.up.pt (P. Tamagnini).

1 Present address: 2C2T - Centro de Ciência e Tecnologia Têxtil, Departamento de Engenharia Têxtil, Universidade do Minho, Campus de Azurém, 4800-058 Guimarães, Portugal.
}

anionic nature due to the presence of two different uronic acids and sulfate groups, and (iii) have high hydrophobicity conferred by the presence of ester-linked acetyl groups, peptidic moieties and deoxysugars (De Philippis, Sili, Paperi, \& Vincenzini, 2001; Shepherd, Rockey, Sutherland, \& Roller, 1995). Altogether, these characteristics make cyanobacterial EPS very attractive for biotechnological applications such as the removal of heavy metal cations from polluted waters. In an industrial context, the use of cyanobacteria (or microbes in general) is advantageous compared to the use of plants or algae, as their growth rates are higher, the costs of production are lower (owing to their minimal nutrition requirements), and their growth conditions are easier to manipulate (Parikh \& Madamwar, 2006; Pereira et al., 2009; Selbmann, Onofri, Fenice, Federici, \& Petruccioli, 2002). Despite all these advantages, the characteristics of the polymers produced are strain-dependent and the number of systematic studies on the conditions that influence EPS production is still scarce, limiting the successful implementation of a biotechnological system based on cyanobacterial EPS (Pereira et al., 2009). Therefore, it is imperative to identify the most advantage EPS-producing cyanobacteria, as well as the culture conditions that influence the synthesis and/or the characteristics of the EPS produced. Previous studies indicate that the presence/absence of combined nitrogen, sulfur, glycerol and aeration, as well as different salt $(\mathrm{NaCl})$ concentrations, temperatures, light intensities and 
light regimens are important factors to be considered, although no systematic studies were performed for a given strain (De Philippis \& Vincenzini, 1998; Pereira et al., 2009). Once the conditions affecting EPS production are identified, the knowledge generated can be used to optimize the productivity and the desirable characteristics of the polymer.

Among EPS-producing cyanobacteria, several members of the Cyanothece genus are described as strong EPS producers (De Philippis, Margheri, Materassi, \& Vincenzini, 1998; Micheletti, Colica, Viti, Tamagnini, \& De Philippis, 2008a; Parikh \& Madamwar, 2006; Shah, Garg, \& Madamwar, 1999). In addition, strains belonging to this genus have been isolated from both freshwaters and marine environments, allowing a given strain to be used for a specific purpose/environment. Nowadays, the study of marine strains is of extreme importance since it allows the exploitation of an abundant resource, saltwater, compared to the scarcity of freshwater.

In this work, a multidisciplinary approach was used to elucidate the conditions that influence EPS production by the unicellular marine $\mathrm{N}_{2}$-fixing Cyanothece sp. CCY 0110, and to characterize the released polymer. Moreover, a scale-up was performed in a $10 \mathrm{~L}$ bioreactor to evaluate the potential use of this strain on an industrial scale.

\section{Materials and methods}

\subsection{Organism and culture conditions}

The cyanobacterium Cyanothece sp. CCY 0110 (Culture Collection of Yerseke, the Netherlands) was grown in $1 \mathrm{~L}$ bioreactors (Stirred reactor, Duran Group GmbH) containing $700 \mathrm{~mL}$ of ASNIII medium (Rippka, Deruelles, Waterbury, Herdman, \& Stanier, 1979). Cultures were generally incubated at $30^{\circ} \mathrm{C}$ under a $12 \mathrm{~h}$ light $\left(20 \mu \mathrm{E} \mathrm{m}^{-2} \mathrm{~s}^{-1}\right) / 12 \mathrm{~h}$ dark regimen, with aeration $\left(1.2 \mathrm{~L} \mathrm{~min}^{-1}\right)$ and magnetic stirring (150 r.p.m.). The light intensity was measured with an Electric Quantum Light Meter (Spectrum Technologies, Inc., USA). The following conditions were assessed, maintaining all the other parameters:

- higher light intensities $\left[12 \mathrm{~h}\right.$ light $\left(50 \mu \mathrm{Em}^{-2} \mathrm{~s}^{-1}\right.$ or $\left.80 \mu \mathrm{E} \mathrm{m}^{-2} \mathrm{~s}^{-1}\right) / 12 \mathrm{~h}$ dark],

- continuous light $\left(20 \mu \mathrm{E} \mathrm{m}^{-2} \mathrm{~s}^{-1}\right.$ or $\left.50 \mu \mathrm{E} \mathrm{m}^{-2} \mathrm{~s}^{-1}\right)$,

- absence of combined nitrogen (ASNIII $)$ (Rippka et al., 1979),

- different temperatures $\left(20^{\circ} \mathrm{C}, 25^{\circ} \mathrm{C}\right.$ or $\left.35^{\circ} \mathrm{C}\right)$,

- extra salt (ASNIII with a final concentration of $5 \%, \mathrm{w} / \mathrm{v}, \mathrm{NaCl}$ ),

- sulfur-limiting conditions (ASNIII with $\mathrm{MgCl}_{2}$ instead of $\mathrm{MgSO}_{4}$ ) (Collier \& Grossman, 1992),

- presence of glycerol (ASNIII plus $10 \mathrm{mM}$ glycerol),

- without aeration,

- air supplemented with $3 \%(\mathrm{v} / \mathrm{v})$ of $\mathrm{CO}_{2}$ (ASNIII supplemented with 40 mM TAPS buffer; pH 8.0).

A 10-fold scale-up was performed for the following conditions: ASNIII medium, $30^{\circ} \mathrm{C}$ under a $12 \mathrm{~h}$ light $\left(50 \mu \mathrm{E} \mathrm{m}^{-2} \mathrm{~s}^{-1}\right.$ and $\left.80 \mu \mathrm{E} \mathrm{m}^{-2} \mathrm{~s}^{-1}\right) / 12 \mathrm{~h}$ dark regimen, with aeration $\left(5 \mathrm{~L} \mathrm{~min}^{-1}\right)$ and magnetic stirring (150 r.p.m.). Cultures were grown in $10 \mathrm{~L}$ bioreactors (Clearboy ${ }^{\mathrm{TM}}$ transparent carboy with magnetic stirrer, Nalgene) containing 7 L of ASNIII medium (Rippka et al., 1979).

\subsection{Optical density and chlorophyll a measurements}

Growth measurements were performed by monitoring the Optical Density (OD) at $730 \mathrm{~nm}$ (Anderson \& McIntosh, 1991) using a SmartSpec 3000, Bio-Rad, and the chlorophyll a content was determined as described by Meeks and Castenholz (1971).

\subsection{Determination of carbohydrate content}

$10 \mathrm{~mL}$ aliquots of the cultures were placed into dialysis membranes (12-14 kDa of molecular weight cutoff; CelluSep ${ }^{\mathrm{R}} \mathrm{T} 4$, Orange Scientific, Belgium) and dialyzed against a minimum of 10 volumes of distilled water for $24 \mathrm{~h}$ with continuous stirring. $5 \mathrm{~mL}$ were used to quantified spectrophotometrically the total carbohydrate content by the phenol-sulfuric acid assay (Dubois, Gilles, Hamilton, Rebers, \& Smith, 1956). The other $5 \mathrm{~mL}$ were used to determine the amount of carbohydrates released to the culture medium (RPS). This was achieved by centrifuging the $5 \mathrm{~mL}$ at $800 \times \mathrm{g}$ for $10 \mathrm{~min}$ at $20^{\circ} \mathrm{C}$, and measuring the carbohydrate content of the supernatant by the method mentioned above. Total carbohydrate and RPS contents are expressed as mg per L of culture and normalized by chlorophyll $a$ content.

\subsection{RPS isolation}

For RPS isolation the cells were grown in ASNIII medium, at $30{ }^{\circ} \mathrm{C}$ under a $12 \mathrm{~h}$ light $\left(50 \mu \mathrm{E} \mathrm{m}^{-2} \mathrm{~s}^{-1}\right) / 12 \mathrm{~h}$ dark regimen and aeration, for 21 or 42 days $\left(\mathrm{OD}_{730 \mathrm{~nm}} 3-5\right)$. The cells were removed by centrifugation at $1700 \times \mathrm{g}$ for $30 \mathrm{~min}$ at $4{ }^{\circ} \mathrm{C}$. The supernatant was dialyzed against a minimum of 10 volumes of distilled water for $48 \mathrm{~h}$ in continuous stirring and the RPS were precipitated with 2 volumes of $96 \%$ cold ethanol, collected with sterile metal forceps and lyophilized.

\subsection{Determination of the monosaccharidic composition}

$5 \mathrm{mg}$ of purified RPS were hydrolyzed with $1 \mathrm{~mL}$ of $2 \mathrm{M}$ trifluoroacetic acid (TFA) at $120^{\circ} \mathrm{C}$ for $2 \mathrm{~h}$, cooled in water, centrifuged at $2400 \times \mathrm{g}$ for $30 \mathrm{~min}$ at $20^{\circ} \mathrm{C}$ using centrifugal filters (Amicon Ultra4 ) and dried in a rotary evaporator. Samples were analyzed by ion exchange chromatography using a Dionex ICS-2500 ion chromatograph (Sunnyvale, CA) with an ED50 pulsed amperometric detector using a gold working electrode (Dionex, Sunnyvale, CA) and a Carbopac PA1 column (Dionex, Sunnyvale, CA). The eluants used were (A) MilliQ-grade water, (B) $0.185 \mathrm{M}$ sodium hydroxide solution and (C) $0.488 \mathrm{M}$ sodium acetate solution. The gradient consisted of a first stage with $84 \%$ solution A, $15 \%$ solution B and $1 \%$ solution C (for $7 \mathrm{~min}$ ); a second stage with $50 \%$ solution $B$ and $50 \%$ solution $C$ (for $9 \mathrm{~min}$ ); and a final stage with $84 \%$ solution A, $15 \%$ solution B and $1 \%$ solution $\mathrm{C}$ (for $14 \mathrm{~min}$ ). The flow rate was $1 \mathrm{~mL} \mathrm{~min}^{-1}$.

\subsection{Determination of RPS fractions}

Purified RPS were dissolved in deionized water and analyzed using a Varian ProStar HPLC chromatograph (Varian, USA) with a 355 IR detector and two columns for Size Exclusion Chromatography (SEC) Polysep-GFC-P 6000 and 4000 (Phenomenex USA), with a flow rate of $0.4 \mathrm{~mL} \mathrm{~min}^{-1}$ for $1 \mathrm{~h}$.

\subsection{Protein/peptide quantification}

$20 \mathrm{mg}$ of RPS were ressuspended in $1 \mathrm{~mL}$ of deionized water, sonicated and successively diluted until a homogeneous solution was obtained. Protein content of the RPS was determined using the Lowry method (Lowry, Rosebrough, Farr, \& Randall, 1951).

\subsection{Fourier transformed infrared (FTIR) spectroscopy}

$2 \mathrm{mg}$ of purified RPS were grinded with $100 \mathrm{mg}$ dry $\mathrm{KBr}$, and pressed into a mold in a uniaxial hydraulic press under a load of 0.9 MPa to obtain IR-transparent pellets. The infrared spectra were recorded with a FTIR system 2000 (Perkin Elmer, USA), 
in transmittance mode in the region of $4000-400 \mathrm{~cm}^{-1}$ and a resolution of $4 \mathrm{~cm}^{-1}$.

\subsection{X-ray diffraction (XRD) analysis}

Diffraction data of isolated RPS was collected with a Gemini PX Ultra (Oxford Diffraction) equipped with $\mathrm{CuK} \alpha$ radiation $(\lambda=1.54184 \AA)$, a 4 -circle kappa goniometer and a CCD Detector. Data collection and processing was carried out using CrysAlisPro Software System (Oxford Diffraction). Crystallinity index $\left(\mathrm{Cl}_{\mathrm{xrd}}\right)$ was estimated determining the area of the crystalline peaks obtained with a Gaussian curve and dividing the total area of the peaks by the total area of the original diffractogram (Mishra, Kavita, \& Jha, 2011). The area of the peaks were estimated according to the XRD amorphous subtraction method (Ruland, 1961).

\subsection{Thermogravimetric analysis (TGA)}

The TGA was carried on a Pyris 1 TGA (Perkin Elmer, USA) according to the standard DIN ISO 11358. The RPS sample was dried at $60^{\circ} \mathrm{C}$ for $1 \mathrm{~h}$ and placed into a porcelain sample pan. The TGA was performed in the range of $25-900{ }^{\circ} \mathrm{C}$, under a nitrogen atmosphere with a flow rate of $20 \mathrm{~mL} \mathrm{~min}^{-1}$ and a heating rate of $10^{\circ} \mathrm{C} \mathrm{min}-1$. Data was plotted as weight loss (\%) vs. temperature.

\subsection{Differential scanning calorimetry (DSC) analysis}

The DSC analysis was carried on Diamond DSC power compensation (Perkin Elmer, USA) with Intracooler ILP according to the standard DIN ISO 11357. The RPS sample was dried at $60^{\circ} \mathrm{C}$ for $1 \mathrm{~h}$ and placed into an aluminum sample pan. The DSC analysis was performed in the range of -90 to $150^{\circ} \mathrm{C}$, under a nitrogen atmosphere with a flow rate of $20 \mathrm{~mL} \mathrm{~min}^{-1}$ and a heating rate of $10^{\circ} \mathrm{C} \mathrm{min}^{-1}$. Data was plotted as heat flow vs. temperature. The temperature at which the RPS starts to decompose was selected as the upper limit for DSC.

\section{Results and discussion}

\subsection{Effect of culture conditions on cell growth and carbohydrate production}

The effects of different environmental/physiological conditions on cell growth and carbohydrate production by Cyanothece sp. CCY 0110 are summarized in Fig. 1. The reproducibility of the experimental workflow was validated through a linear regression analysis performed on the data obtained for each one of the biological triplicates of the "control" condition $\left[30^{\circ} \mathrm{C}, 12 \mathrm{~h}\right.$ light $\left(20 \mu \mathrm{E} \mathrm{m}^{-2} \mathrm{~s}^{-1}\right) / 12 \mathrm{~h}$ dark regimen, aeration and magnetic stirring], which unveiled a $R^{2}$ of 0.959 for cell growth (optical density) and 0.941 for carbohydrate production. In all cases, the cell growth and amount of total carbohydrates present in the culture (intracellular carbohydrates plus RPS) followed the same pattern. The RPS constitute in average $74 \pm 4 \%$ of the total carbohydrates in all conditions tested. This cyanobacterial strain does not possess a sheath or capsule, only produces RPS, which are easier to recover compared to the polymers that remain attached to the cell surface, conferring an advantage to its potential use in biotechnological applications.

Cyanothece sp. CCY 0110 does not exhibit a typical bacterial growth curve with a clear exponential phase. This phenomenon is not unusual for cyanobacteria, and has been previously observed for strains that produce large amounts of extracellular polysaccharides (Pereira et al., 2011a; Yu, Jia, \& Dai, 2010). All cultures were grown with aeration since this condition was shown to be vital to cell survival in this type of bioreactors (data not shown), probably due to a
A

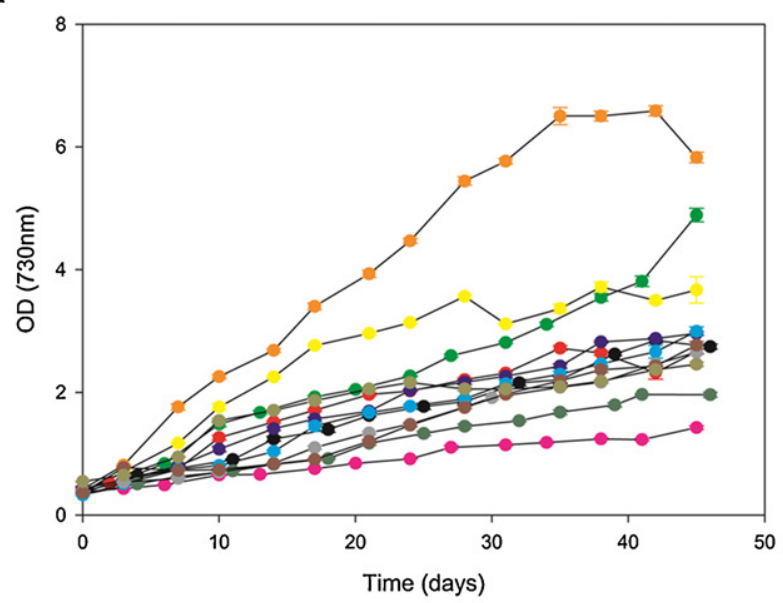

B

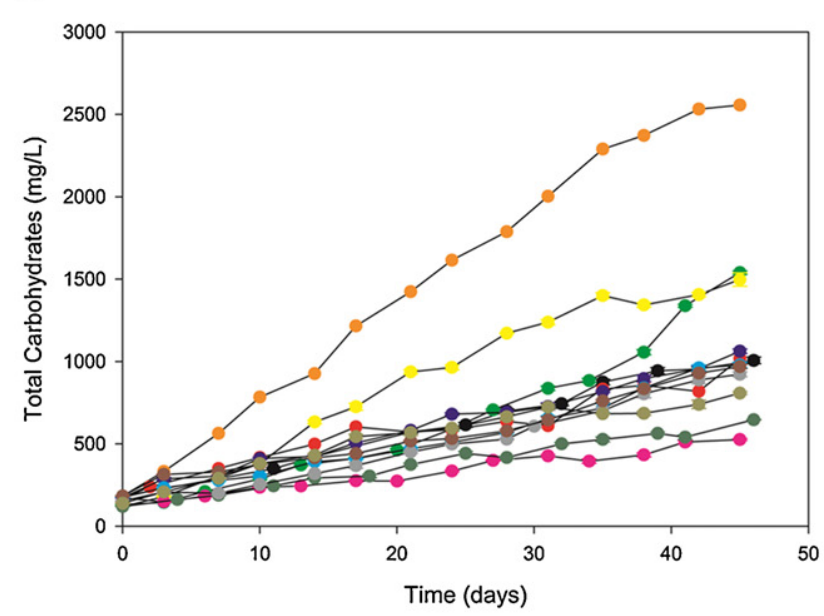

Fig. 1. Growth curves of Cyanothece sp. CCY 0110 (A) and amount of total carbohydrates expressed as mg per L of culture (B). Cultures were grown in ASNIII medium, with a $12 \mathrm{~h}$ light $\left(20 \mu \mathrm{E} \mathrm{m}^{-2} \mathrm{~s}^{-1}\right) / 12 \mathrm{~h}$ dark regimen, $30^{\circ} \mathrm{C}$ and aeration $(\bullet)$, or with the modifications highlighted in red (for details see Section 2). (For interpretation of the references to color in this figure legend, the reader is referred to the web version of the article.)

low rate of gas exchange. Moreover, the aeration promotes a better stirring of the culture, increasing the exposure of the cells to the light (Pereira et al., 2009). Maximum cell growth and carbohydrate production ( $2.6 \mathrm{~g}$ of total carbohydrates $\mathrm{L}^{-1}$ ) were obtained for the cultures grown under high light intensity $\left(50 \mu \mathrm{E} \mathrm{m}^{-2} \mathrm{~s}^{-1}\right)$ and $12 \mathrm{~h}$ light $/ 2 \mathrm{~h}$ dark regimen. When this regimen is changed to continuous light, the growth and carbohydrate production decreases. This result suggests that an excess of light is prejudicial to the cells, for e.g. disrupting the circadian rhythms. In agreement, starting cultures with an even higher light intensity $\left(80 \mu \mathrm{E} \mathrm{m}^{-2} \mathrm{~s}^{-1}\right)$ has also a deleterious effect leading to cell death (data not shown) (Pereira et al., 2011b). Possibly, the cultures could be grown at higher light 
intensities if the intensity is increased gradually. On the other hand, for cultures grown under lower light intensity $\left(20 \mu \mathrm{E} \mathrm{m}^{-2} \mathrm{~s}^{-1}\right)$ continuous light has a positive effect on growth and carbohydrate production. Overall, these results strongly suggest that light is the key factor affecting Cyanothece sp. CCY 0110 growth and, consequently carbohydrate production. This is in agreement with previous studies that report that EPS production is enhanced by continuous light and high light intensities, suggesting that energy availability is one of the main factors controlling the EPS biosynthesis in cyanobacteria (Nicolaus et al., 1999; Otero \& Vincenzini, 2003; Pereira et al., 2009). In addition to the hypothesis that the higher carbohydrate production constitutes a mechanism of releasing the excess of energy absorbed by the cell under high light intensities, it should also be point out that the increased carbohydrate levels may constitute a protecting mechanism triggered by the cells. In $\mathrm{N}_{2}$-fixing conditions (medium without combined nitrogen) the cell growth and carbohydrate production decrease significantly, probably because the $\mathrm{N}_{2}$ fixing process requires large amounts of energy, resulting in less energy available for growth and carbohydrate production. This effect was also observed for other cyanobacterial strains, notably Nostoc sp. PCC 7413 (Otero \& Vincenzini, 2003). Moreover, in other strains nitrogen starvation has been shown to contribute to the increase of the C: $\mathrm{N}$ ratio, promoting the incorporation of carbon into the carbohydrates needed for the cell and, consequently, decreasing the energy availability for their growth (De Philippis et al., 1998; Nicolaus et al., 1999; Pereira et al., 2009). Cyanothece sp. CCY 0110 exhibited similar growth at $20^{\circ} \mathrm{C}, 25^{\circ} \mathrm{C}$ and $30^{\circ} \mathrm{C}$. However, an increase to $35^{\circ} \mathrm{C}$ lead to a growth impair, as well as a decrease in the amount of carbohydrates produced, indicating that exceeding the optimum temperature acts as a stress factor (Trabelsi, Ben Ouada, Bacha, \& Ghoul, 2009). The two-fold increase in $\mathrm{NaCl}$ concentration did not produce a significant effect in growth and carbohydrate production, probably due to the fact that Cyanothece sp. CCY 0110 thrives in a marine environment (marine coast of Tanzania), therefore being able to tolerate high concentrations of salt. Although in other cyanobacterial strains, such as Cyanothece sp. ATCC 51142, Synechocystis spp., Spirulina sp., and Anabaena sp. PC-1, an increase of $\mathrm{NaCl}$ acts as a stress factor promoting EPS production (Nicolaus et al., 1999; Ozturk \& Aslim, 2010; Pereira et al., 2009). Likewise, sulfur-limited conditions did not affect significantly cell growth and carbohydrate production. It has been previously reported that sulfur depletion can lead to slow growth rate due to incorporation of the sulfur in the Gloeothece sp. PCC 6909 polysaccharidic sheath (Ortega-Calvo \& Stal, 1994). However, one should bear in mind that Cyanothece sp. CCY 0110 releases its polysaccharides to the culture medium and does not have a structured sheath or capsule. Neither glucose (data not shown) nor glycerol affected significantly the cells growth and carbohydrate production. This result contrasts with that observed for Cyanothece sp. ATCC 51142, in which the presence of glycerol increases biomass (Feng et al., 2010), emphasizing the idea that the responses of cyanobacteria to changes in culture conditions are strain-dependent. Similarly, aerating the cultures with $\mathrm{CO}_{2}$ (instead of only air) did not affect significantly growth and carbohydrate production, suggesting that aeration alone provides the necessary carbon to the cells. These last observations suggest that there is no carbon limitation to the cells.

In order to establish a correlation between the culture conditions tested and the amount of carbohydrates produced per cell, the amount of carbohydrates was normalized to chlorophyll $a$ values (Fig. 2). The chlorophyll $a$ content was proved to be a good estimation of cell density, showing a linear relation with OD values (e.g. "control" condition with a $R^{2}$ of 0.984 and best condition obtained with a $R^{2}$ of 0.979$)$. Generally, the amount of carbohydrates produced per chlorophyll $a$ (and consequently per cell) did not vary significantly in all the conditions tested. These results strongly suggest that the variation in the amount of carbohydrates present in
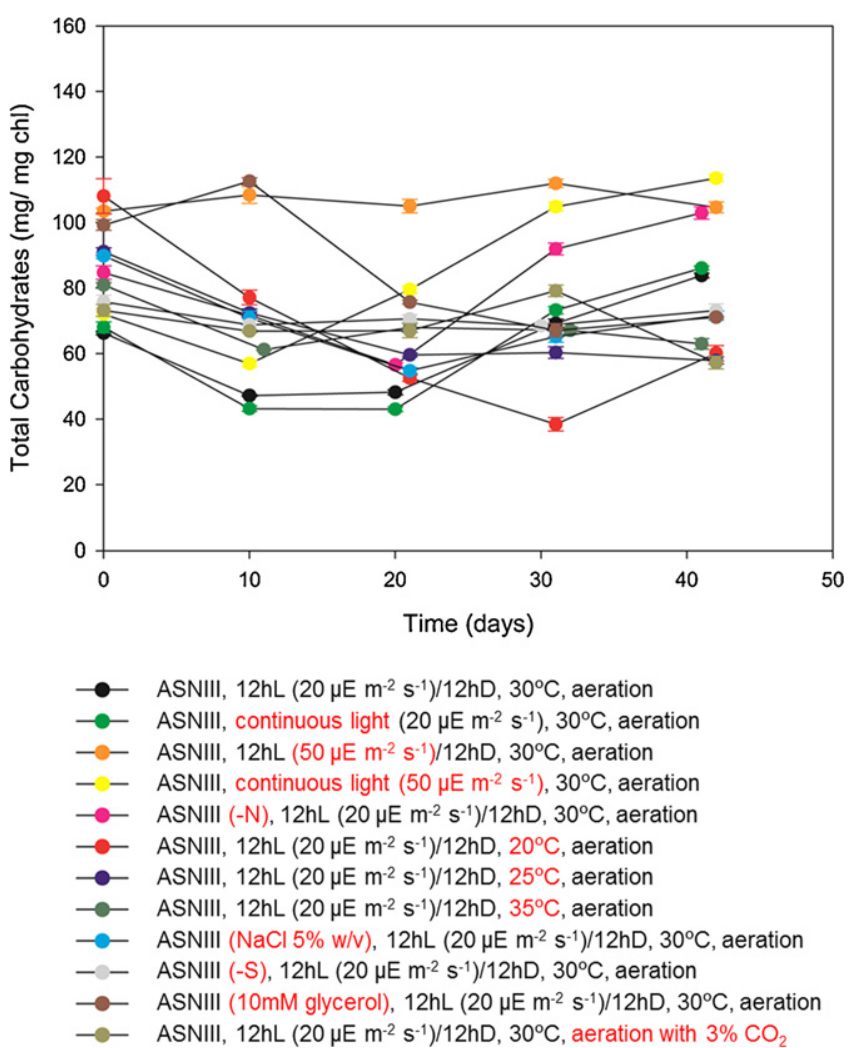

Fig. 2. Total carbohydrates content of Cyanothece sp. CCY 0110 cells, expressed as $\mathrm{mg}$ of carbohydrates per mg of chlorophyll $a$. Cultures were grown in ASNIII medium, with a $12 \mathrm{~h}$ light $\left(20 \mu \mathrm{E} \mathrm{m}^{-2} \mathrm{~s}^{-1}\right) / 12 \mathrm{~h}$ dark regimen, $30^{\circ} \mathrm{C}$ and aeration $(\bullet)$, or with the modifications highlighted in red (for details see Section 2). (For interpretation of the references to color in this figure legend, the reader is referred to the web version of the article.)

the culture is mainly related to the number of cells, rather than on the amount of carbohydrates produced by each cell. An exception was observed for the cultures supplemented with glycerol, where an initial enhancement of carbohydrate production was observed (data not shown), which is consistent with an increase of the intracellular carbon pools. This effect was only transient, probably due to the complete consumption of the glycerol added.

Due to the lack of normalization of the data available in the literature, the comparison of our data with values obtained for other cyanobacteria grown under different conditions is not straightforward. However, our results strongly emphasize that Cyanothece sp. CCY 0110 is an efficient RPS producer, reaching $1.8 \mathrm{~g} \mathrm{~L}^{-1}$ of culture. This value is within the highest obtained for other RPS-producing cyanobacteria and that of some representative EPS-producing lactic acid bacteria (Table 1) (Ruas-Madiedo \& de los Reyes-Gavilan, 2005).

Table 1

Amount of RPS or EPS produced by some cyanobacteria and lactic acid bacteria.

\begin{tabular}{|c|c|c|}
\hline Cyanobacteria & $\operatorname{RPS}\left(\mathrm{mg} \mathrm{L}^{-1}\right)$ & Reference \\
\hline Cyanothece sp. CCY 0110 & 1770 & This work \\
\hline Cyanothece CA 3 & 2360 & De Philippis et al. (1998) \\
\hline Nostoc calcicola RDU-3 & 700 & Singh and Das (2011) \\
\hline Anabaena WSAF & 55 & Nicolaus et al. (1999) \\
\hline Lactic acid bacteria & $\mathrm{EPS}\left(\mathrm{mg} \mathrm{L}^{-1}\right)$ & Reference \\
\hline $\begin{array}{l}\text { Streptococcus thermophilus } \\
\text { ChH. YC-380 }\end{array}$ & 600 & $\begin{array}{l}\text { Ruas-Madiedo and de los } \\
\text { Reyes-Gavilan (2005) }\end{array}$ \\
\hline Lactobacillus sakei 0-1 & 1580 & $\begin{array}{l}\text { Ruas-Madiedo and de los } \\
\text { Reyes-Gavilan (2005) }\end{array}$ \\
\hline
\end{tabular}



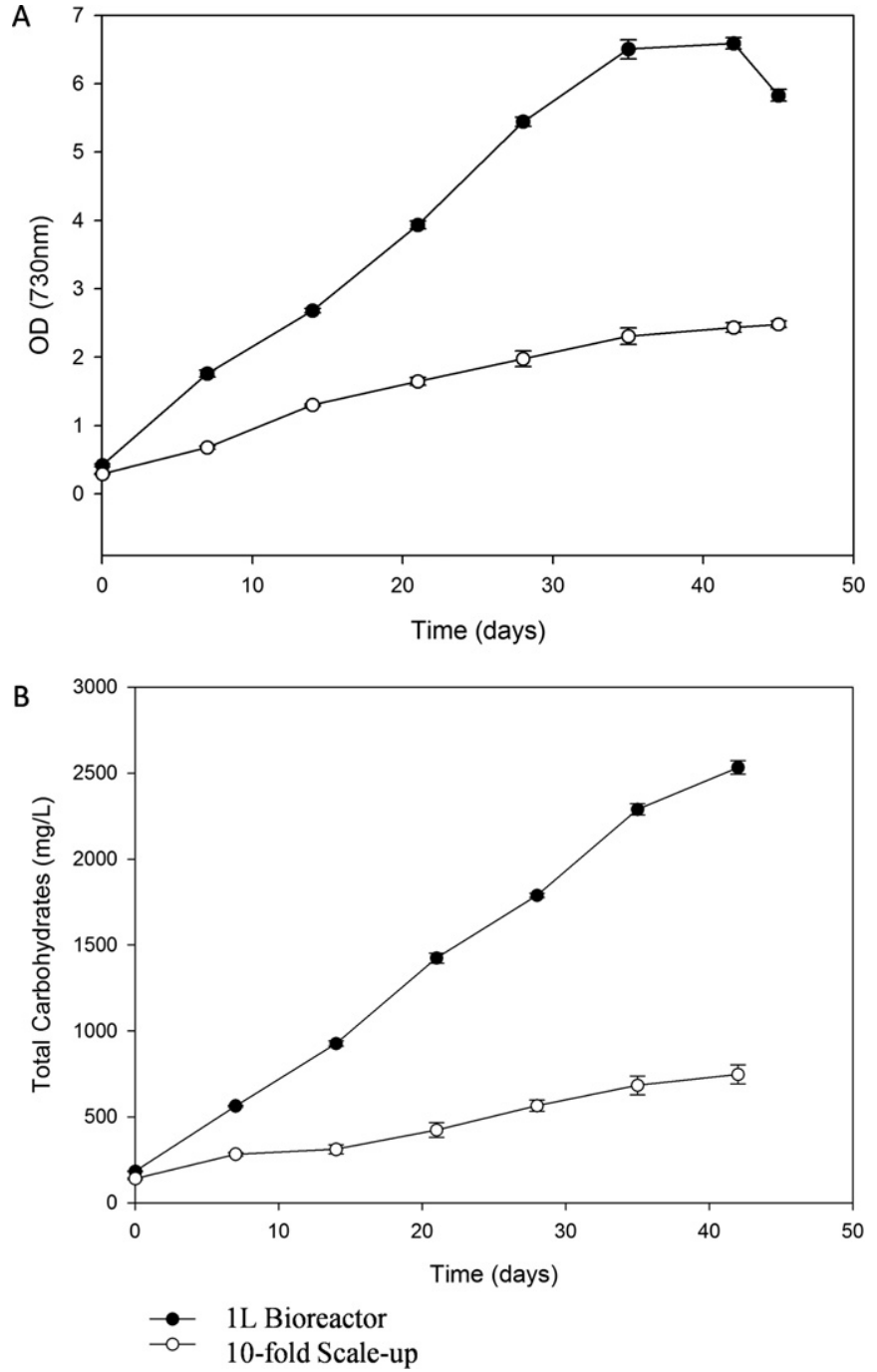

Fig. 3. Growth curves of Cyanothece sp. CCY 0110 (A) and amount of total carbohydrates expressed as $\mathrm{mg}$ per L of culture (B) grown in a bioreactor $(\bullet)$ or in a 10 -fold scale-up ( $\bigcirc$ ). Cultures were grown in ASNIII medium, with a $12 \mathrm{~h}$ light $\left(50 \mu \mathrm{E} \mathrm{m}^{-2} \mathrm{~s}^{-1}\right) / 12 \mathrm{~h}$ dark regimen, $30^{\circ} \mathrm{C}$ and aeration.

A 10-fold scale-up was performed in conditions that favor carbohydrate production (presence of nitrate in the medium, $30^{\circ} \mathrm{C}$ under a $12 \mathrm{~h}$ light $\left(50 \mu \mathrm{E} \mathrm{m}^{-2} \mathrm{~s}^{-1}\right) / 12 \mathrm{~h}$ dark regimen and aeration). The results obtained for the growth and carbohydrate production were approximately three times lower than in $1 \mathrm{~L}$ bioreactors (Fig. 3). These values increased slightly when the light intensity was changed to $80 \mu \mathrm{E} \mathrm{m}^{-2} \mathrm{~s}^{-1}$ (data not shown). This limitation is probably due to the $10 \mathrm{~L}$ bioreactor material (polycarbonate) and its geometry (smaller surface:area ratio than the $1 \mathrm{~L}$ ones), that hamper the light penetration/distribution. Other type of bioreactors can be advantageous to large-scale production, namely flat panel or tubular photobioreactors (Dutta, De, Chaudhuri, \& Bhattacharya, 2005).

\subsection{RPS characterization}

The RPS isolated from cultures grown in the best producing condition (presence of nitrate in the medium, $30^{\circ} \mathrm{C}$ under a $12 \mathrm{~h}$ light $\left(50 \mu \mathrm{E} \mathrm{m}^{-2} \mathrm{~s}^{-1}\right) / 12 \mathrm{~h}$ dark regimen and aeration) were characterized. The samples were collected at two different time points: middle of the growth curve ( 21 days) and stationary phase (42 days). In general, the results obtained were identical for most of

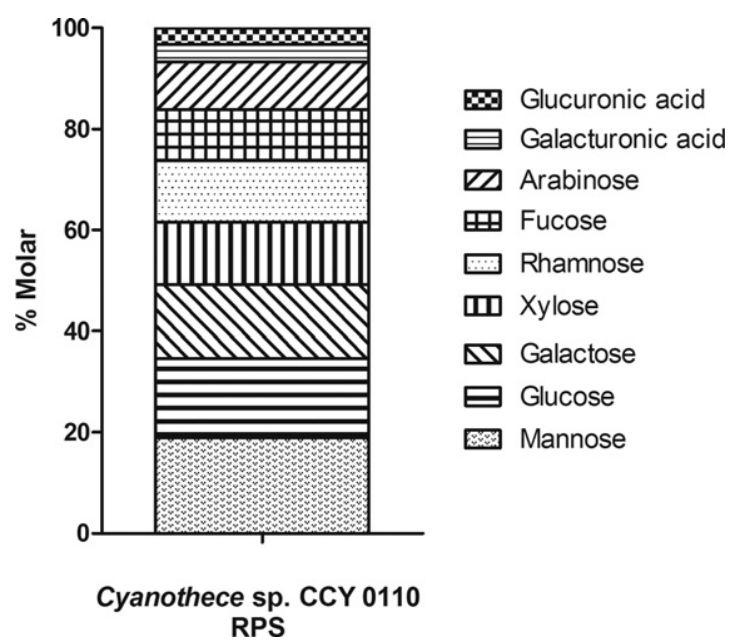

Fig. 4. Monosaccharidic composition (expressed as molar\%) of the RPS produced by Cyanothece sp. CCY 0110. Cultures were grown during 42 days in ASNIII medium, with a $12 \mathrm{~h}$ light $\left(50 \mu \mathrm{E} \mathrm{m}^{-2} \mathrm{~s}^{-1}\right) / 12 \mathrm{~h}$ dark regimen, $30^{\circ} \mathrm{C}$ and aeration.

the parameters evaluated. In those cases, only the results for the 42 days are present for simplification.

\subsection{Monosaccharidic composition of Cyanothece sp. CCY 0110 RPS}

Nine different monosaccharides were found in the RPS produced by Cyanothece sp. CCY 0110: the hexoses mannose, glucose and galactose; the pentoses xylose and arabinose; the deoxyhexoses rhamnose and fucose; and the acidic hexoses galacturonic and glucuronic acids (Fig. 4). The highly heterogeneous composition of the RPS produced by this strain is in agreement with the complexity observed for cyanobacterial polymers that can contain up to different 13 residues (Pereira et al., 2009). The predominance of mannose (19\%) and the presence of pentoses (22\%; usually absence in other EPS of prokaryotic origin), in Cyanothece RPS are in agreement with that observed for several strains including Nostoc sp. and Oscillatoria formosa (Jindal, Singh, \& Khattar, 2011; Mishra et al., 2011; Parikh \& Madamwar, 2006; Pereira et al., 2009). Other remarkable characteristics of these polymers are the presence of two different uronic acids (7\%), which confer a high affinity for positively charged molecules (e.g. metal cations) and the presence of deoxyhexoses (22\%), which increases the hydrophobicity of the polymer. These percentages are comparable to the values previously observed in the RPS of Gloeothece sp. PCC 6909 (13\% and 11\% for uronic acids and deoxyhexoses, respectively) (Micheletti et al., 2008b).

\subsection{Determination of RPS fractions}

The HPLC-SEC analysis revealed that the RPS produced by Cyanothece sp. CCY 0110 are composed by two different fractions, with molecular mass of about $5000 \mathrm{kDa}$ and $1500 \mathrm{kDa}$. These values are only estimates since the analysis may be affected by the high viscosity of the polymer. Nevertheless, the two apparent molecular masses are significantly higher than those obtained for the polymers produced by other cyanobacteria and that of xanthan gum, which is about $1000 \mathrm{kDa}$ (Pereira et al., 2009).

\subsection{Protein/peptide quantification}

The amount of protein and/or peptides present in the RPS produced by Cyanothece sp. CCY 0110 is different in the two samples collected in the different time points. The protein content in the 21 days RPS sample was $7.7 \pm 0.13 \%$ of RPS dry weight, while at 


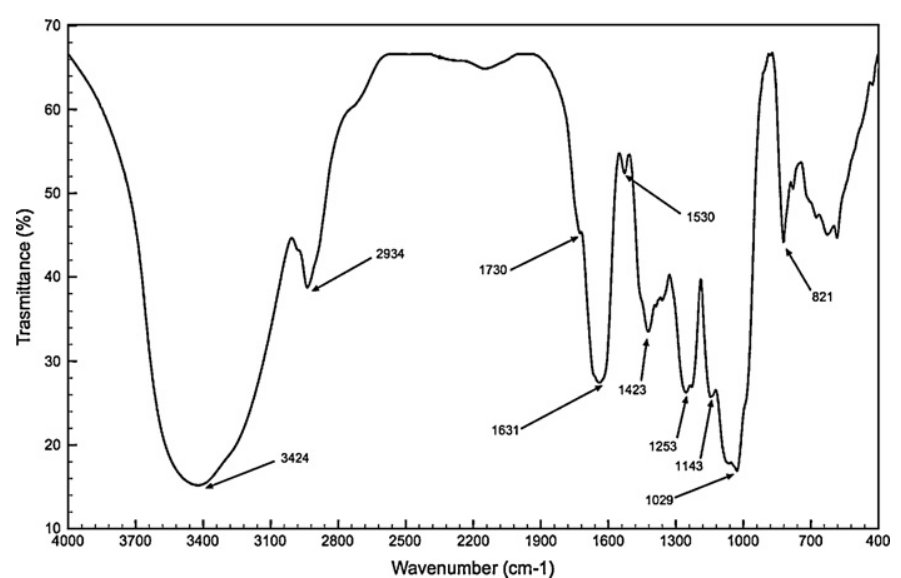

Fig. 5. Fourier transformed infrared (FTIR) spectrum of RPS isolated from Cyanothece sp. CCY 0110. Cultures were grown during 42 days in ASNIII medium, with a $12 \mathrm{~h}$ light $\left(50 \mu \mathrm{E} \mathrm{m}^{-2} \mathrm{~s}^{-1}\right) / 12 \mathrm{~h}$ dark regimen, $30^{\circ} \mathrm{C}$ and aeration. Arrows indicate the major absorptions bands and the corresponding wavenumbers.

the 42 days was only $1.7 \pm 0.20 \%$. These values are similar to the ones obtained for other cyanobacterial strains, like Gloeothece sp. (Micheletti et al., 2008b). The lower value at 42 days is not surprising since at this point the protein fraction of the RPS was probably undergoing some degradation, due to the natural increase of lysed cells that released proteases to the culture medium. The decrease in the amount of protein/peptide content in contrast with the amount of RPS produced (Fig. 1) suggests that these proteins/peptides are loosely associated to the RPS.

\subsection{Fourier transformed infrared (FTIR) spectroscopy}

The FTIR spectra of the RPS produced by Cyanothece sp. CCY 0110 revealed several characteristic absorption bands (Fig. 5, arrows). The weak absorption band at $2934 \mathrm{~cm}^{-1}$ is characteristic of the $\mathrm{C}-\mathrm{H}$ stretching vibration of $\mathrm{CH}_{2}$, and the band at $1423 \mathrm{~cm}^{-1}$ of the $\mathrm{C}-\mathrm{H}$ bending of $\mathrm{CH}_{2}$ or $\mathrm{CH}_{3}$, all bands typical of carbohydrates (Parikh \& Madamwar, 2006; Yee, Benning, Phoenix, \& Ferris, 2004). The accentuated band at $3424 \mathrm{~cm}^{-1}$ can be attributed to the stretching vibration of the hydroxyl $(-\mathrm{OH})$ or amine $(-\mathrm{NH})$ groups, whereas the prominent absorption at $1631 \mathrm{~cm}^{-1}$ and the weak at $1530 \mathrm{~cm}^{-1}$ can be related to the vibration of amide groups (Parikh \& Madamwar, 2006; Yee et al., 2004). The presence of the amine and amide groups confirms that the polymer is not only constituted by polysaccharides, but also comprises some peptides and/or proteins (see above) (Pagnanelli, Papini, Toro, Trifoni, \& Veglio, 2000). Moreover, since the spectrum obtained is similar for the 21 and 42 days samples, these observations reinforce the hypothesis that the proteins/peptides are loosely associated to the RPS. The bands at $1253 \mathrm{~cm}^{-1}$ and $1029 \mathrm{~cm}^{-1}$ can be attributed to the asymmetrical and symmetrical $\mathrm{S}=0$ stretching vibration, respectively, whereas the bands at $1143 \mathrm{~cm}^{-1}$ and $821 \mathrm{~cm}^{-1}$ are likely due to the asymmetrical and symmetrical $\mathrm{C}-\mathrm{O}-\mathrm{S}$ vibration. These data are consistent with the presence of sulfate groups in the Cyanothece's RPS, as generally observed for other cyanobacterial polymers (Mahner, Lechner, \& Nordmeier, 2001; Silva et al., 2005; Yee et al., 2004; Zou et al., 2008). The peak at $1730 \mathrm{~cm}^{-1}$ is indicative of the $\mathrm{C}=\mathrm{O}$ stretching vibration typical of uronic acids, which is in agreement with the data obtained for the RPS monosaccharidic composition, where both glucuronic and galacturonic acids were detected. Overall, these findings strongly suggest that RPS from Cyanothece sp. CCY 0110 contain uronic acids, sulfate groups and peptides in their composition.

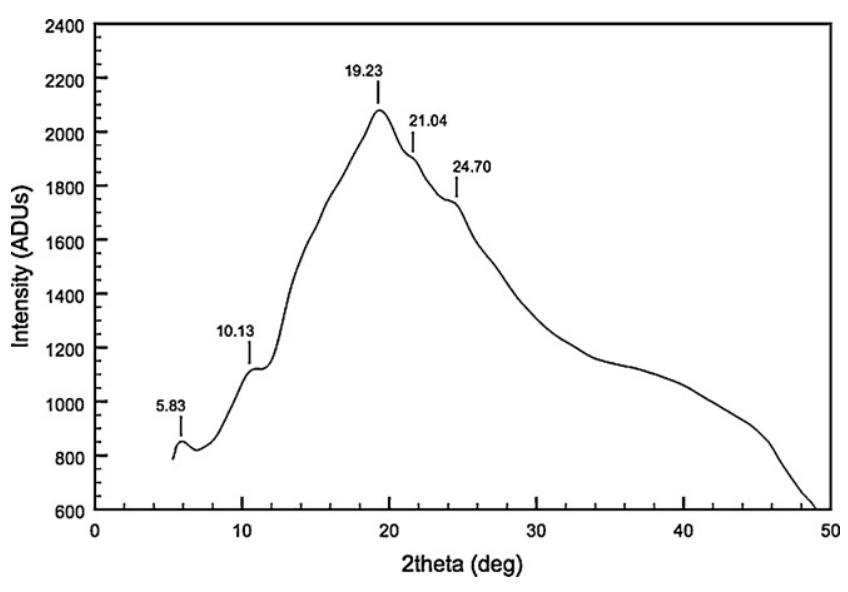

Fig. 6. X-ray diffraction pattern of the RPS isolated from Cyanothece sp. CCY 0110. Cultures were grown during 42 days in ASNIII medium, with a $12 \mathrm{~h}$ light $\left(50 \mu \mathrm{E} \mathrm{m}^{-2} \mathrm{~s}^{-1}\right) / 12 \mathrm{~h}$ dark regimen, $30^{\circ} \mathrm{C}$ and aeration. Values correspond to the diffraction peaks, expressed as degrees.

\subsection{X-ray diffraction (XRD) analysis}

The XRD profile of RPS produced by Cyanothece sp. CCY 0110 exhibited a broad characteristic peak with weak diffraction peaks at $5.83^{\circ}, 10.13^{\circ}, 19.23^{\circ}, 21.04^{\circ}$ and $24.70^{\circ}$ (Fig. 6), with interplanar spacing ( $d$-spacing) of $15.1,8.7,4.6,4.2$ and 3.6 $\AA$, respectively. The XRD pattern revealed a low crystallinity index of about 0.04 , which demonstrates the amorphous nature of the RPS. The pattern exhibited by the RPS produced by this strain is similar to the profiles obtained for amorphous polymers produced by other microorganism (Kavita, Mishra, \& Jha, 2011; Mishra et al., 2011).

\subsection{Thermogravimetric analysis (TGA)}

The TGA revealed that the degradation of RPS produced by Cyanothece sp. CCY 0110 occurs in three distinct phases (Fig. 7). Similar patterns have already been observed for other cyanobacterial EPS, including those produced by Cyanothece sp. ATCC 51142 and Nostoc spp., as well as for other polymers such as xanthan gum and guar gum (Parikh \& Madamwar, 2006). In the initial phase (phase I) the polymer showed a weight loss of $12 \%$ as the temperature rose from $20^{\circ} \mathrm{C}$ to $110^{\circ} \mathrm{C}$, probably due to dehydration. As

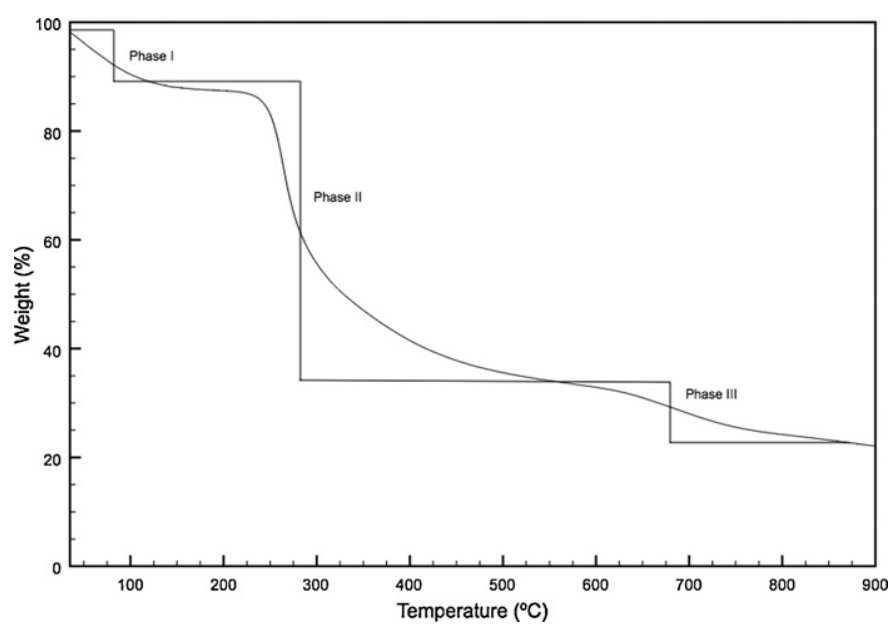

Fig. 7. Thermogravimetric analysis (TGA) of the RPS isolated from Cyanothece sp. CCY 0110. Cultures were grown during 42 days in ASNIII medium, with a $12 \mathrm{~h}$ light $\left(50 \mu \mathrm{E} \mathrm{m}^{-2} \mathrm{~s}^{-1}\right) / 12 \mathrm{~h}$ dark regimen, $30^{\circ} \mathrm{C}$ and aeration. The analysis was performed at a heating rate of $10^{\circ} \mathrm{C} \mathrm{min}^{-1}$. The three differentiated degradation phases obtained are delimitated in the figure. 
the temperature further increased, the weight remained relatively constant until the system reached $248^{\circ} \mathrm{C}$, when the polysaccharide started to decompose (phase II) until approximately $300^{\circ} \mathrm{C}$. At this point, the total weight loss reached about $65 \%$. The third phase (phase III) occurred from 582 to $765^{\circ} \mathrm{C}$, with an additional $10 \%$ weight loss, and can be attributed to the degradation of the remaining inorganic material. The high thermostability, with the consequent high solid residue content (21\%), may be due to the complex and heterogeneous molecular structure of the RPS, including the presence of sulfate groups and uronic acids, which prevented complete degradation of the polymer (Alves, Caridade, Mano, Sousa, \& Reis, 2010; Pooja \& Chandra, 2009). The thermal performance of the RPS produced by Cyanothece sp. CCY 0110 (ca. $275^{\circ} \mathrm{C}$ ) envisages a remarkable resistance to a wide range of temperatures, as observed for other polymers (Alves et al., 2010; Mishra et al., 2011; Parikh \& Madamwar, 2006).

\subsection{Differential scanning calorimetry (DSC) analysis}

The DSC analysis of the RPS produced by Cyanothece sp. CCY 0110 did not exhibit any crystallization or fusion peaks (data not shown), confirming the amorphous nature of the RPS produced.

\section{Conclusions}

Overall, the results obtained in this work show that Cyanothece sp. CCY 0110 is among the most efficient EPS producers, releasing the majority of the carbohydrates into the culture medium (RPS fraction $\sim 75 \%$ ). Moreover, we clearly demonstrated that the amount of carbohydrates/RPS produced are mainly related to the number of cells (growth), rather than to the amount produced by each cell. Light was shown to be the key parameter, with high light intensity enhancing significantly the amount of carbohydrates produced (reaching $1.8 \mathrm{gRPS}^{-1}$ ). Temperatures between $20^{\circ} \mathrm{C}$ and $30^{\circ} \mathrm{C}$ are suitable for growth/RPS production. The presence of combined nitrogen increases significantly growth/RPS production compared to nitrogen-fixing conditions. The analysis of the RPS produced by this strain revealed nine different monosaccharides (including two uronic acids, two pentoses and two deoxyhexoses), the presence of sulfate groups and peptides. The polymer is composed by two different fractions, remarkably thermostable and of amorphous nature. In general, this work highlights the special features of the polymer and the potential of an efficient RPS producer - Cyanothece sp. CCY 0110 - for biotechnological applications.

\section{Acknowledgments}

This work was funded by FEDER funds through the Operational Competitiveness Programme - COMPETE and by National Funds through FCT - Fundação para a Ciência e a Tecnologia under the projects FCOMP-01-0124-FEDER-022718 (PEst-C/SAU/LA0002/2011), FCOMP-01-0124-FEDER-009389 (PTDC/CTM/100627/2008) and FCOMP-01-0124-FEDER-009697 (PTDC/EBB-EBI/099662/2008) and grants SFRH/BPD/37045/2007 and SFRH/BPD/72400/2010. We would also like to thank to Lucas Stal for providing Cyanothece sp. CCY 0110 and Margarida Brito for helpful discussion and comments about data interpretation.

\section{References}

Alves, A., Caridade, S. G., Mano, J. F., Sousa, R. A., \& Reis, R. L. (2010). Extraction and physico-chemical characterization of a versatile biodegradable polysaccharide obtained from green algae. Carbohydrate Research, 345, 2194-2200.

Anderson, S. L., \& McIntosh, L. (1991). Light-activated heterotrophic growth of the cyanobacterium Synechocystis sp. strain PCC 6803: a blue-light-requiring process. Journal of Bacteriology, 173, 2761-2767.
Collier, J. L., \& Grossman, A. R. (1992). Chlorosis induced by nutrient deprivation in Synechococcus sp. strain PCC 7942: not all bleaching is the same. Journal of Bacteriology, 174, 4718-4726.

De Philippis, R., Margheri, M. C., Materassi, R., \& Vincenzini, M. (1998). Potentia of unicellular cyanobacteria from saline environments as exopolysaccharide producers. Applied and Environmental Microbiology, 64, 1130-1132.

De Philippis, R., Sili, C., Paperi, R., \& Vincenzini, M. (2001). Exopolysaccharideproducing cyanobacteria and their possible exploitation: A review. Journal of Applied Phycology, 13, 293-299.

De Philippis, R., \& Vincenzini, M. (1998). Exocellular polysaccharides from cyanobacteria and their possible applications. FEMS Microbiology Reviews, 22, 151-175.

Dubois, M., Gilles, K. A., Hamilton, J. K., Rebers, P. A., \& Smith, F. (1956). Colorimetric method for determination of sugars and related substances. Analytical Chemistry $28,350-356$

Dutta, D., De, D., Chaudhuri, S., \& Bhattacharya, S. K. (2005). Hydrogen production by Cyanobacteria. Microbial Cell Factories, 4, 36.

Feng, X., Bandyopadhyay, A., Berla, B., Page, L., Wu, B., Pakrasi, H. B., \& Tang, Y. J. (2010). Mixotrophic and photoheterotrophic metabolism in Cyanothece sp. ATCC 51142 under continuous light. Microbiology, 156, 2566-2574.

Jindal, N., Singh, D. P., \& Khattar, J. I. S. (2011). Kinetics and physico-chemica characterization of exopolysaccharides produced by the cyanobacterium Oscillatoria formosa. World Journal of Microbiology and Biotechnology, 27. 2139-2146.

Kavita, K., Mishra, A., \& Jha, B. (2011). Isolation and physico-chemical characterisation of extracellular polymeric substances produced by the marine bacterium Vibrio parahaemolyticus. Biofouling, 27, 309-317.

Lowry, O. H., Rosebrough, N. J., Farr, A. L., \& Randall, R. J. (1951). Protein measurement with the Folin phenol reagent. The Journal of Biological Chemistry, 193, 265-275.

Mahner, C., Lechner, M. D., \& Nordmeier, E. (2001). Synthesis and characterisation of dextran and pullulan sulphate. Carbohydrate Research, 331, 203-208.

Meeks, J. C., \& Castenholz, R. W. (1971). Growth and photosynthesis in an extreme thermophile, Synechococcus lividus (Cyanophyta). Archiv fur Mikrobiologie, 78, 25-41.

Micheletti, E., Colica, G., Viti, C., Tamagnini, P., \& De Philippis, R. (2008). Selectivity in the heavy metal removal by exopolysaccharide-producing cyanobacteria. Journal of Applied Microbiology, 105, 88-94.

Micheletti, E., Pereira, S., Mannelli, F., Moradas-Ferreira, P., Tamagnini, P., \& De Philippis, R. (2008). Sheathless mutant of cyanobacterium Gloeothece sp. strain PCC 6909 with increased capacity to remove copper ions from aqueous solutions. Applied and Environmental Microbiology, 74, 2797-2804.

Mishra, A., Kavita, K., \& Jha, B. (2011). Characterization of extracellular polymeric substances produced by micro-algae Dunaliella salina. Carbohydrate Polymers, 83, 852-857.

Nicolaus, B., Panico, A., Lama, L., Romano, I., Manca, M. C., De Giulio, A., \& Gambacorta A. (1999). Chemical composition and production of exopolysaccharides from representative members of heterocystous and non-heterocystous cyanobacteria. Phytochemistry, 52, 639-647.

Ortega-Calvo, J. J., \& Stal, L. J. (1994). Sulphate-limited growth in the $\mathrm{N}_{2}$-fixing unicellular cyanobacterium Gloeothece (Nageli) sp. PCC 6909. New Phytologist, 128, $273-281$.

Otero, A., \& Vincenzini, M. (2003). Extracellular polysaccharide synthesis by Nostoc strains as affected by N source and light intensity. Journal of Biotechnology, 102, $143-152$.

Ozturk, S., \& Aslim, B. (2010). Modification of exopolysaccharide composition and production by three cyanobacterial isolates under salt stress. Environmental Science and Pollution Research International, 17, 595-602.

Pagnanelli, F., Papini, M. P., Toro, L., Trifoni, M., \& Veglio, F. (2000). Biosorption of metal ions on Arthrobacter sp.: Biomass characterization and biosorption modeling. Environmental Science \& Technology, 34, 2773-2778.

Parikh, A., \& Madamwar, D. (2006). Partial characterization of extracellular polysaccharides from cyanobacteria. Bioresource Technology, 97, 1822-1827.

Parker, D. L., Schram, B. R., Plude, J. L., \& Moore, R. E. (1996). Effect of metal cations on the viscosity of a pectin-like capsular polysaccharide from the cyanobacterium Microcystis flos-aquae C3-40. Applied and Environmental Microbiology, $62,1208-1213$.

Pereira, S., Micheletti, E., Zille, A., Santos, A., Moradas-Ferreira, P., Tamagnini, P., \& De Philippis, R. (2011). Using extracellular polymeric substances (EPS)-producing cyanobacteria for the bioremediation of heavy metals: do cations compete for the EPS functional groups and also accumulate inside the cell? Microbiology, 157, 451-458.

Pereira, S., Zille, A., Micheletti, E., Moradas-Ferreira, P., De Philippis, R., \& Tamagnini, P. (2009). Complexity of cyanobacterial exopolysaccharides: composition, structures, inducing factors and putative genes involved in their biosynthesis and assembly. FEMS Microbiology Reviews, 33, 917-941.

Pereira, S. B., Ow, S. Y., Barrios-Llerena, M. E., Wright, P. C., Moradas-Ferreira, P., \& Tamagnini, P. (2011). iTRAQ-based quantitative proteomic analysis of Gloeothece sp. PCC 6909: comparison with its sheathless mutant and adaptations to nitrate deficiency and sulfur limitation. Journal of Proteomics, 75, 270-283.

Pooja, K. P., \& Chandra, T. S. (2009). Production and partial characterization of a novel capsular polysaccharide KP-EPS produced by Paenibacillus pabuli strain ATSKP. World Journal of Microbiology and Biotechnology, 25, 835-841.

Rippka, R., Deruelles, J., Waterbury, J. B., Herdman, M., \& Stanier, R. Y. (1979). Generic assignments, strain histories and properties of pure cultures of cyanobacteria. Journal of General Microbiology, 111, 1-61. 
Ruas-Madiedo, P., \& de los Reyes-Gavilan, C. G. (2005). Invited review: methods for the screening, isolation, and characterization of exopolysaccharides produced by lactic acid bacteria. Journal of Dairy Science, 88, 843-856.

Ruland, W. (1961). X-ray determination of crystallinity and diffuse disorder scattering. Acta Crystallographica, 14, 1180-1185.

Selbmann, L., Onofri, S., Fenice, M., Federici, F., \& Petruccioli, M. (2002). Production and structural characterization of the exopolysaccharide of the Antarctic fungus Phoma herbarum CCFEE 5080. Research in Microbiology, 153, 585-592.

Shah, V., Garg, N., \& Madamwar, D. (1999). Exopolysaccharide production by a marine cyanobacterium Cyanothece sp.: Application in dye removal by its gelation phenomenon. Applied Biochemistry and Biotechnology, 82, 81-90.

Shepherd, R., Rockey, J., Sutherland, I. W., \& Roller, S. (1995). Novel bioemulsifiers from microorganisms for use in foods. Journal of Biotechnology, 40, 207-217.

Silva, T. M., Alves, L. G., de Queiroz, K. C., Santos, M. G., Marques, C. T., Chavante, S. F., Rocha, H. A., \& Leite, E. L. (2005). Partial characterization and anticoagulant activity of a heterofucan from the brown seaweed Padina gymnospora. Brazilian Journal of Medical and Biological Research, 38, 523-533.
Singh, S., \& Das, S. (2011). Screening, production, optimization and characterization of cyanobacterial polysaccharide. World Journal of Microbiology and Biotechnology, 27, 1971-1980.

Sutherland, I. W. (1999). Polysaccharases for microbial exopolysaccharides. Carbohydrate Polymers, 38, 310-328.

Trabelsi, L., Ben Ouada, H., Bacha, H., \& Ghoul, M. (2009). Combined effect of temperature and light intensity on growth and extracellular polymeric substance production by the cyanobacterium Arthrospira platensis. Journal of Applied Phycology, 21, 405-412.

Yee, N., Benning, L. G., Phoenix, V. R., \& Ferris, F. G. (2004). Characterization of metal-cyanobacteria sorption reactions: a combined macroscopic and infrared spectroscopic investigation. Environmental Science E Technology, 38, 775-782.

Yu, H., Jia, S., \& Dai, Y. (2010). Accumulation of exopolysaccharides in liquid suspension culture of Nostoc flagelliforme cells. Applied Biochemistry and Biotechnology, $160,552-560$.

Zou, C., Du, Y., Li, Y., Yang, J., Feng, T., Zhang, L., \& Kennedy, J. F. (2008). Preparation of lacquer polysaccharide sulfates and their antioxidant activity in vitro. Carbohydrate Polymers, 73, 322-331. 